\title{
FAKTOR-FAKTOR YANG MEMPENGARUHI PENERIMAAN PAJAK PENGHASILAN BADAN PADA KANTOR PELAYANAN PAJAK DI KOTA BANJARMASIN
}

\author{
ARIS SETIA NOOR DAN BERTA LESTARI \\ Fakultas Ekonomi Universitas Islam Kalimantan Muhammad Arsyad Al-Banjary, Banjarmasin
}

The purpose of this study are: (1) To find out how much the influence of tax climate on the receipt of corporate income tax partially, (2) To find out how much influence the tax climate on corporate income tax revenue together. The research method used is survey research method. Data collection techniques used the census method. Data collection is done through direct observation to the object of research and literature study. The method of analysis used in this study is Path Analysis. Based on data used the statistic analistic shows that: (1) Simultaneously to fulfill and convey clearly and accurately the tax form, to account correctly the debt tax, to pay the debt tax at the right time give positive and significant to 5\% real standard toward the acceptance of income tax body. (2) Partially to fulfill and convey clearly and accurately the tax form, to account correctly the debt tax, to pay the debt tax at the right time give positive and insignificant to $5 \%$ real standard toward the acceptance of income tax body.The result of this research shows that other unaccounted variable has very small affect in the amount of $0.32 \%$ toward acceptance of income tax body.

Keywords: Tax Climate, Income of Corporate Income Tax 


\section{PENDAHULUAN}

Salah satu usaha untuk mewujudkan kemandirian suatu bangsa atau negara dalam pembiayaan pembangunan yaitu dengan menggali sumber dana yang ada, yang berasal dari dalam negeri berupa pajak. Masalah pajak adalah masalah negara, masyarakat dan setiap orang yang tinggal dalam negara dan masyarakat harus berurusan dengan pajak serta menjadi tanggung jawab bersama. Pajak merupakan salah satu sumber penerimaan negara yang penting dan ikut menentukan sumbangan fungsionalnya bagi efektivitas kelancaran roda pemerintahan.

Upaya pemerintah Indonesia terus berlangsung dalam upaya proses pemulihan ekonomi negara, peranan kebijakan fiskal menjadi semakin penting dan menjadi tumpuan utama dalam menunjang penerimaan negara. Pendapatan negara yang bersumber dari pajak pada tahun 2010 adalah sebesar Rp. 183 triliun, tahun 2011 jumlah ini meningkat menjadi Rp. 213 triliun, dengan demikian terjadi peningkatan sebesar Rp. 30 triliun atau kenaikan sebesar 16\%. Tahun 2010 dalam rancangan RUU APBN pemerintah menargetkan peningkatan pendapatan dari pajak sebesar Rp. 21 triliun sehingga pendapatan pajak diharapkan menjadi Rp. 234 triliun atau terjadi kenaikan sebesar 10\% dibanding tahun 2011 atau sebesar 28\% dibanding tahun 2012 (Eric \& Suwarta, 2012).

Pada dasarnya tidak ada satu pun dari verifikasi atau metode teknis lainnya dapat diperluas sampai mencapai jumlah wajib pajak yang cukup, agar diperoleh efek langsung yang berpengaruh terhadap penerimaan pajak atau menjamin tercapainya kepatuhan membayar pajak yang cukup tinggi. Prosedur teknis tersebut memang berperan dalam mengurangi penyelundupan pajak, akan tetapi yang diharapkan adalah agar prosedur tersebut dapat membantu pembentukan akal sehat para wajib pajak yang pada akhirnya akan menghasilkan kepatuhan membayar pajak.

Meskipun Instansi Pajak telah pula melibatkan penggunaan para ahli perpajakan dalam memasukan uang pajak, namun yang menjadi dasar dari semua fungsi tersebut adalah terutama penciptaan Iklim Perpajakan (tax climate) yang sehat. Iklim perpajakan itu sendiri adalah suatu faktor yang tidak berwujud (intangible factor) dalam keseimbangan antara usaha bertahan untuk tidak membayar pajak (tax resistance) dan kesadaran serta kepatuhan memenuhi kewajiban perpajakan (tax compliance) menurut Mohammad Zain (2009).

Sistem pemungutan pajak yang dianut di Indonesia saat ini adalah sistem self assessment yaitu ketetapan pajak yang ditetapkan oleh wajib pajak sendiri yang dilakukannya dalam Surat Pemberitahuan (SPT). Ciri dan corak dari sistem pemungutan pajak, wajib pajak diwajibkan menghitung, memperhitungkan, dan membayar sendiri jumlah pajak yang seharusnya terutang sesuai dengan ketentuan peraturan perundang-undangan perpajakan, sehingga penentuan besarnya pajak yang terutang berada pada Wajib Pajak sendiri. Selain daripada itu Wajib Pajak diwajibkan pula melaporkan secara teratur jumlah pajak yang terutang dan yang telah dibayar sebagaimana ditentukan dalam peraturan perundangan-undangan perpajakan.

Tetapi fenomena yang terjadi pada Kantor Pelayanan Pajak Kota Banjarmasin yang menyebabkan belum tercipta dan berkembangnya Iklim Perpajakan yang sehat yaitu tingkat kepatuhan dari Wajib Pajak dalam memenuhi serta mematuhi peraturan perundang-undangan perpajakan, kepatuhan dari Wajib Pajak dalam menyampaikan Surat Pemberitahuan. Salah satu bentuk kepatuhan memenuhi kewajiban perpajakan adalah kepatuhan penyampaian Surat Pemberitahuan (SPT). Berdasarkan data yang diperoleh dari KPP Kota Banjarmasin diketahui bahwa tingkat kepatuhan Wajib Pajak dalam menyampaikan SPT PPh tahun 2011-2016 cenderung menurun.

\section{TINJAUAN PUSTAKA}

\section{Iklim Perpajakan}

Pada dasarnya tidak ada satu pun dari verifikasi atau metode teknis lainnya dapat diperluas sampai mencapai jumlah wajib pajak yang cukup, agar diperoleh efek langsung yang berpengaruh terhadap penerimaan pajak atau menjamin tercapainya kepatuhan membayar pajak yang cukup tinggi. Prosedur teknik tersebut memang berperan dalam mengurangi penyelundupan pajak, akan tetapi yang diharapkan adalah agar prosedur terse- 
but dapat membantu pembentukan akal sehat para wajib pajak yang pada akhirnya akan menghasilkan kepatuhan pemenuhan kewajiban perpajakan para wajib pajak.

Meskipun instansi pajak telah pula melibatkan penggunaan para ahli perpajakan, keuangan negara, hukum, ekonomi, akuntan dan teknisi-teknisi lainnya dalam usaha memasukan uang pajak, namun yang menjadi dasar dari semua fungsi tersebut, adalah terutama penciptaan "iklim perpajakan" (tax climate) yang sehat.

Menurut Mohammad Zain (2009:31) "Iklim perpajakan itu sendiri adalah suatu faktor yang tidak berwujud (intangible factor) dalam keseimbangan antara usaha bertahan untuk tidak membayar pajak (tax resistance) dan kesadaran serta kepatuhan memenuhi kewajiban perpajakan (tax compliance).

Pengertian diatas bahwa iklim perpajakan tersebut sebagian besar merupakan hasil dari keberhasilan administrasi perpajakan yang terdiri dari beberapa unsur dalam sistem perpajakan tersebut dalam suatu periode waktu tertentu dan hal ini bukanlah sesuatu yang muncul begitu saja, tetapi harus dikembangkan melalui iklim perpajakan.

Faktor dominan yang berpengaruh atas perkembangan iklim perpajakan yang sehat dan berada diluar jangkauan administrasi perpajakan, adalah faktor "state of mind" yang mempengaruhi kemauan (willingness) wajib pajak pajak untuk memenuhi kewajiban perpajakannya, yang tidak akan berkembang begitu saja tanpa pemerintah khususnya Dirjen Pajak menyadari betapa pentingnya hal tersebut dan mengadakan program yang luas dan berkesinambungan untuk mempengaruhi perubahan dan perkembangannya yang tentunya harus disesuaikan dengan kondisi dan situasi negara masing-masing.

Beberapa faktor penting yang dapat mempengaruhi pengembangan "state of mind" yang dilakukan oleh instansi pajak, tergantung antara lain kemampuan untuk meyakinkan para Wajib Pajak tentang 3 (tiga) hal menurut Norman D. Nowak (2015:15):

1. The realization by the taxpayer that he gets something for his tax money-roads, school, hospital, etc.
2. A general respect for the govermentin terms of the ability and willingness of government to carry out all its law impartially.

3. The economic policy of the government regarding each sector paying its taxes in a reasonable and just proportion to the rest of the economy.

Salamun A.T. mengungkapkan bahwa penghindaran pajak (tidak patuh dalam memasukan Surat Pemberitahuan (SPT), sengaja tidak memahami peraturan perundang-undangan perpajakan maupun menangguhkan pajak) yang dilakukan oleh Wajib Pajak, tidak terlepas dari pengalaman pahit di masa lalu yang masih terbawa.

Menurut Mohammad Zain (2009:32) beberapa pendekatan penting lainnya dalam rangka penciptaan iklim perpajakan yang sehat tersebut, yang dapat dilakukan oleh instansi pajak dan merupakan tanggung jawabnya untuk dikembangkan, adalah:

1. Sistem Perpajakan yang Adil

Pada umumnya kepatuhan memenuhi kewajiban perpajakan, adalah sistem perpajakan yang "adil" dan sampai saat ini masalah "apa" dan "bagaimana" sesungguhnya yang dikatakan adil tersebut tetap merupakan masalah, baik bagi pemerintah maupun para Wajib Pajak. Apabila semua penduduk membayar pajak sesuai kemampuannya dan bahwa setiap orang akan mempunyai tempat dan perlakuan yang sama apabila mereka memenuhi perpajakannya, namun satu hal yang tetap menjadi masalah besar adalah menyangkut "berapa besarnya" jumlah pajak tersebut untuk dapat dianggap sebagai pengenaan yang adil. Seberapa besar pengaruh iklim perpajakan terhadap penerimaan pajak penghasilan wajib pajak badan secara parsial dan Seberapa besar pengaruh iklim perpajakan terhadap penerimaan pajak penghasilan wajib pajak badan secara bersama-sama

\section{Sanksi Administrasi dan Pidana}

Wajib pajak merasa akan mendapat ancaman hukuman dalam hal dia diketahui oleh instansi pajak bahwa dia melakukan penyelundupan pajak. Berkenaan dengan hal ini beberapa administrator pajak berpendapat bahwa sesungguhnya tidak diperlukan suatu tindakan apapun, apabila dengan rasa takut hukuman saja wajib pajak sudah akan memenuhi kewajibannya, namun hal ini sangat 
tergantung kepada kebudayaan masing-masing negara dan merupakan persoalan negara yang bersangkutan untuk memutuskan mana yang terbaik untuk negaranya.

Perasaan takut akan tertangkap dan dipenjarakan akibat penyelundupan pajak merupakan alat pencegah yang ampuh untuk mengurangi penyelundupan pajak. Apabila timbul perasaan tidak akan berbuat kesalahan dalam kaitannya dengan pelaksanaan ketentuan peraturan perundang-undangan perpajakan sudah berkembang dikalangan para wajib pajak, hal ini berarti menuju ke kepatuhan dan kesadaran untuk memenuhi kewajibannya perpajakannya, sudah terbuka.

3. Pelayanan dan Bantuan Terhadap Wajib Pajak

Dalam usaha mengembangkan iklim perpajakan yang sehat, ialah mengembangkan dan meningkatkan pelayanan terhadapa wajib pajak. Dari sudut pandang lain, hal ini mempunyai nilai tambah untuk tidak membiarkan adanya dalih bagi pembayar pajak untuk tidak membayar pajak dan hal ini berarti pula bahwa tidaklah cukup kalau hanya meminta kepada pembayar pajak agar mematuhi ketentuan peraturan perundang-undangan perpajakan, tetapi sesungguhnya instansi pajak pun bertanggung jawab atas segala pemberian informasi yang diperlukan dan petugas pajak harus siap setiap saat untuk membantu para pembayar pajak mengisi Surat Pemberitahuan (SPT) dan lain-lain yang berhubungan dengan pemenuhan kewajiban perpajakan.

4. Reputasi Petugas Pajak

Langkah-langkah yang diambil terdahulu yaitu para petugas pajak hendaknya memiliki sebagai tujuannya "mencapai reputasi yang baik sepanjang yang menyangkut kecakapan teknis, efisien dan efektif dalam hal kecepatan, tepat dan keputusan yang adil".

Bagaimanapun juga semua petugas pajak hendaknya menyadari bahwa semua tindakan yang dilakukannya serta sikapnya terhadap pembayar pajak dalam rangka pelaksanaan tugasnya, mempunyai pengaruh langsung terhadap kepercayaan masyarakat akan sistem perpajakan secara keseluruhan.

\section{Program Informasi (Information Program)}

Baik program jangka pendek maupun program jangka panjang memerlukan dukungan program informasi yang tersebar luas yang meliputi antara lain:

- Apa yang diperoleh pembayar pajak dari uang pajaknya

- Peranannya sebagai pembayar pajak dalam pembangunan

- Pendidikan bagi anak-anak usia muda di sekolah-sekolah tentang perlunya pajak.

- Semua tindakan penerangan lainnya yang perlu untuk meletakan dasar-dasar bagi diterimanya pajak sebagai suatu keharusan di masa-masa sekarang dan masa-masa mendatang.

6. Data-data Kepatuhan Memenuhi Kewajiban Perpajakan

Ukuran efektifitas suatu administrasi perpajakan diukur dari tinggi rendahnya tingkat penyelundupan pajak, baik secara keseluruhan maupun per jenis pajak. Hal ini memang tidaklah mudah dilaksanakan, namun demikian hendaklah diperhatikan bahwa tanpa adanya data tentang penyelundupan pajak atau data tentang tingkat kepatuhan memenuhi kewajiban perpajakan, instansi pajak tidak mempunyai dasar yang kokoh untuk suatu perencanaan yang efektif.

\section{Pajak Penghasilan Badan}

Pengertian pajak penghasilan menurut Rimsky K. Judisseno (2015) adalah "Suatu pungutan resmi yang ditujukan kepada masyarakat yang berpenghasilan atau atas penghasilan yang diterima dan diperolehnya dalam tahun pajak untuk kepentingan negara dan masyarakat dalam hidup berbangsa dan bernegara sebagai suatu kewajiban yang harus dilaksanakan."

Menurut Pratt (2015), "Net income is difference between the revenues generated by a company in a particular time period and the expenses required to generate those revenues."

\section{Objek Pajak}

Yang menjadi objek pajak menurut pasal 4 ayat (1) UU. No. 17 Tahun 2008 tentang perubahan ketiga atas Undang-Undang No. 7 tahun 2008 tentang Pajak Penghasilan adalah penghasilan, yaitu setiap tambahan ekonomis yang diterima atau diperoleh Wajib Pajak baik yang berasal dari Indonesia maupun dari luar Indonesia yang dapat dipakai untuk konsumsi atau menambah kekayaan 
Wajib Pajak yang bersangkutan dengan nama dan dalam bentuk apapun.

Yang termasuk dalam pengertian penghasilan UU. No. 17 Tahun 2008 tentang perubahan ketiga atas Undang-Undang No. 7 tahun 2008 tentang Pajak Penghasilan adalah:

1. Penggantian atau imbalan berkenaan dengan pekerjaan atau jasa yang diterima atau diperoleh termasuk gaji, upah, honorarium, komisi, bonus, gratifikasi, uang pensiun, atau imbalan dalam bentuk lainnya, kecuali ditentukan lain dalam Undang-undang ini.

2. Hadiah dari undian atau pekerjaan atau kegiatan, dan penghargaan.

3. Laba Usaha

4. Keuntungan karena penjualan atau karena pengalihan harta termasuk:

- Keuntungan karena pengalihan harta kepada perseroan, persekutuan, dan badan lainnya sebagai pengganti saham atau penyertaan modal.

- Keuntungan yang diperoleh perseroan, persekutuan dan badan lainnya karena pengalihan harta kepada pemegang saham, sekutu, atau anggota.

- Keuntungan karena likuidasi, penggabungan, peleburan, pemekaran, pemecahan, atau pengambilalihan usaha.

- Keuntungan karena pengalihan harta berupa hibah, bantuan atau sumbangan, kecuali diberikan kepada keluarga sedarah dalam garis keturunan lurus satu derajat, dan badan keagamaan atau badan pendidikan atau badan sosial atau pengusaha kecil termasuk koperasi yang ditetapkan oleh Menteri Keuangan, sepanjang tidak ada hubungan dengan usaha, pekerjaan, kepemilikan atau penguasaan antara pihak-pihak yang bersangkutan;

5. Penerimaan kembali pembayaran pajak yang telah dibebankan sebagai biaya.

6. Bunga termasuk premium, diskonto, dan imbalan lain karena jaminan pengembalian uang.

7. Dividen, dengan nama dan bentuk apapun, termasuk dividen dari perusahaan asuransi kepada pemegang polis dan pembagian sisa hasil usaha koperasi.

8. Royalti.
9. Sewa dan penghasilan lain sehubungan dengan penggunaan harta.

10. Penerimaan atau perolehan pembayaran berkala.

11. Keuntungan karena pembebasan utang, kecuali sampai dengan jumlah tertentu yang ditetapkan dengan Peraturan Pemerintah.

12. Keuntungan karena selisih kurs mata uang asing.

13. Selisih lebih karena penilaian kembali aktiva.

14. Premi asuransi.

15. Iuran yang diterima atau diperoleh perkumpulan dari anggotanya yang terdiri dari Wajib Pajak yang menjalankan usaha atau pekerjaan bebas.

16. Tambahan kekayaan netto yang berasal dari penghasilan yang belum dikenakan pajak.

\section{METODOLOGI PENELITIAN}

Metode analisis data yang dipergunakan dalam penelitian ini adalah menggunakan Alat Analisis Jalur (Path Analysis). Alasan menggunakan teknik analisis path adalah karena terdapat kaitan korelasional antar variabel bebas, sehingga dapat diduga terdapat pengaruh langsung dan tidak langsung terhadap variabel terikat.

Untuk menentukan besarnya pengaruh suatu variabel terhadap variabel lainnya baik itu pengaruh yang sifatnya langsung maupun yang tidak langsung menurut Sewall Wright (2010) yang dikutip oleh Harun Al Rasjid (2012) dalam buku Analisis Jalur (Path Analysis) maka dapat digunakan Analisis Jalur (Path Analysis). Teknik analisis ini memerlukan syarat data yang mempunyai tingkat pengukuran sekurang-kurangnya interval, adapun keempat variabel tersebut yaitu terdiri dari kepatuhan menyampaikan mengisi formulir pajak dengan lengkap dan jelas sebagai $\left(X_{1}\right)$, kepatuhan menghitung jumlah pajak yang terutang dengan benar sebagai $\left(X_{2}\right)$, kepatuhan membayar pajak terutang tepat waktunya sebagai $\left(X_{3}\right)$, dan penerimaan pajak penghasilan wajib pajak badan (PPh Badan) sebagai variabel $Y$, di mana semua variabel tersebut memiliki skala rasio.

Adapun langkah kerja Analisis jalur yang disarankan untuk diikuti seperti yang dikemukakan oleh Harun Al Rasjid (2012) adalah sebagai berikut: 
1. Gambarkan dengan jelas diagram jalur yang mencerminkan proposisi hipotetik yang diajukan, lengkap dengan persamaan strukturalnya sehingga bisa tampak jelas variabel apa saja yang merupakan variabel eksogenus dan apa yang menjadi variabel endogenusnya. Gambar diagram jalur penelitian ini adalah sebagai berikut:

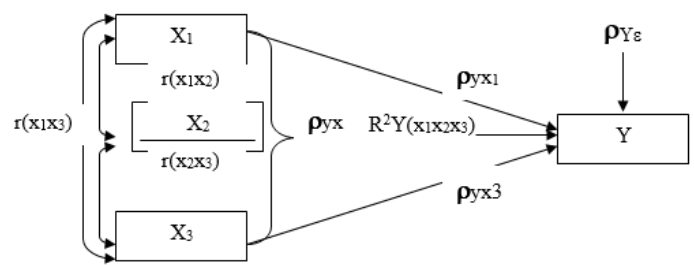

2. Hitung matrik korelasi antar variabel.

$$
\mathrm{R}=\left[\begin{array}{cccc}
\mathrm{X}_{1} & \mathrm{X}_{2} & \mathrm{X}_{3} & \mathrm{Y} \\
1 & { }^{\mathrm{r}} \mathrm{x}_{1 \times 2} & { }^{\mathrm{r}} \mathrm{x}_{1} \mathrm{x}_{3} & { }^{\mathrm{r}} \mathrm{x}_{1} \mathrm{y} \\
{ }^{\mathrm{r}} \mathrm{x}_{2} \mathrm{x}_{1} & 1 & { }^{\mathrm{r}} \mathrm{X}_{2} \mathrm{X}_{3} & { }^{\mathrm{r}} \mathrm{x}_{2 \mathrm{y}} \\
{ }^{\mathrm{r}} \mathrm{x}_{3} \mathrm{x}_{1} & { }^{\mathrm{r}} \mathrm{X}_{3} \mathrm{x}_{2} & 1 & { }^{\mathrm{r}} \mathrm{X}_{4} \mathrm{X}_{1} \\
{ }^{\mathrm{r}} \mathrm{yx}_{1} & { }^{\mathrm{r}} \mathrm{yx}_{2} & { }^{\mathrm{r}} \mathrm{yx} 3 & 1
\end{array}\right]
$$

3. Identifikasikan sub-struktur dan persamaan yang akan dihitung koefisien jalurnya. Misalkan saja dalam sub-struktur yang telah kita identifikasi terdapat $\mathrm{k}$ buah variabel eksogenus, dan sebuah (selalu hanya sebuah) variabel endogenus $\mathrm{Y}$ yang dinyatakan oleh persamaan.

$\mathrm{Y}=\rho_{\mathrm{yx}_{1} \mathrm{X}_{1}}+\rho_{\mathrm{yx}_{2} \mathrm{X}_{2}}+\rho_{\mathrm{yx}_{3} \mathrm{X}_{3}}+\varepsilon$

4. Hitung matriks korelasi antar variabel eksogenus yang menyusun sub struktur tersebut.

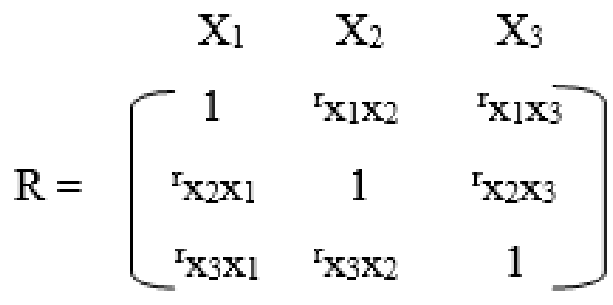

5. Hitung matriks invers $\mathrm{R}^{-1}$

$$
R^{-1}=C_{i i}=\left[\begin{array}{lll}
\mathrm{X}_{1} & \mathrm{X}_{2} & \mathrm{X}_{3} \\
\mathrm{C}_{11} & \mathrm{C}_{12} & \mathrm{C}_{13} \\
\mathrm{C}_{21} & \mathrm{C}_{22} & \mathrm{C}_{23}
\end{array}\right]
$$

6. Hitung semua koefisien jalur $x_{\mathrm{i}}, \mathrm{i}=1,2,3,4$ melalui rumus :

$\left[\begin{array}{c}\rho_{\mathrm{yx} 1} \\ \rho_{\mathrm{yx} 2} \\ \rho_{\mathrm{yx} 3}\end{array}\right]\left[\begin{array}{lll}\mathrm{C}_{11} & \mathrm{C}_{12} & \mathrm{C}_{13} \\ \mathrm{C}_{21} & \mathrm{C}_{22} & \mathrm{C}_{23} \\ \mathrm{C}_{31} & \mathrm{C}_{32} & \mathrm{C}_{33}\end{array}\right]\left[\begin{array}{c}{ }_{\mathrm{xy}} \\ { }^{\mathrm{r}} \mathrm{xy} 2 \\ { }^{\mathrm{r} \mathrm{xy} 3}\end{array}\right]$

7. Hitung $\mathrm{R}^{2} \mathrm{y}\left(\mathrm{x}_{1}, \mathrm{x}_{2}, \ldots, \mathrm{x}_{\mathrm{k}}\right)$ yaitu koefisien yang menyatakan Determinasi Total $\mathrm{x}_{1}, \mathrm{x}_{2}, \mathrm{x}_{3}$ (dalam analisis regresi koefisien ini disebut Koefisien Determinasi Multipel), dengan menggunakan rumus :

$\mathrm{R}^{2} \mathrm{y}\left(\mathrm{x}_{1,2}, \mathrm{x}_{2}\right)=\left(\begin{array}{lll}\rho_{\mathrm{xy} 1} & \rho_{\mathrm{xy} 2} & \rho_{\mathrm{xy}}\end{array}\right) \quad\left[\begin{array}{c}\mathrm{r}_{\mathrm{xy} 1} \\ \mathrm{r}_{\mathrm{xy} 2} \\ \mathrm{r}_{\mathrm{xy} 3}\end{array}\right]$

Rumus Koefisien Determinasi Total

8. Hitung ${ }^{{ }^{\rho}} \mathrm{y}_{\varepsilon}$ (koefisien jalur variabel lainnya) berdasarkan rumus berikut :

$$
\rho_{\mathrm{y} \varepsilon}=\sqrt{1-\mathrm{R}_{\mathrm{y}\left(\mathrm{x}_{1}, \mathrm{x}_{2}, \mathrm{x}_{3}\right)}^{2}}
$$

Rumus Koefisien Jalur Variabel lainnya

Sumber : Harun Al-Rasjid (2012)

\section{HASIL DAN PEMBAHASAN}

\section{Analsis Hasil}

Gambar di bawah ini menunjukan besarnya koefesien jalur antar variabel :

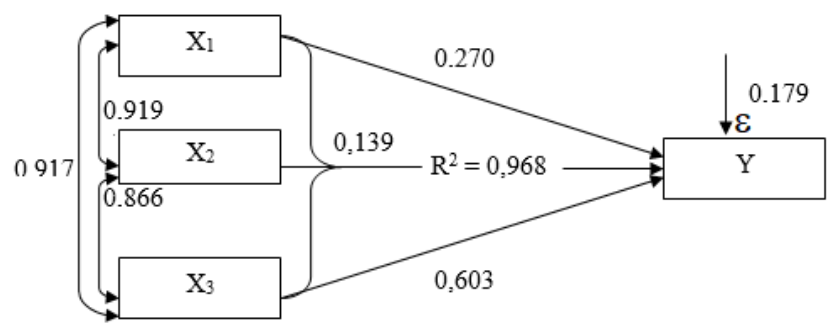

Matrix korelasi antara variabel $\mathrm{X}$ dengan $\mathrm{Y}$ yang diperoleh atas dasar data pada tabel yang terdapat pada Lampiran ( Lisrel 8.70 pada Correlation Matrix to be Analyzed

Tabel 1

Matrix Korelasi Antara X dengan $Y$

\begin{tabular}{ccccc}
\hline & $\mathbf{X}_{1}$ & $\mathbf{X}_{2}$ & $\mathbf{X}_{3}$ & $\mathbf{Y}$ \\
\hline $\mathbf{X}_{1}$ & 1,000 & 0,919 & 0,917 & 0,950 \\
\hline $\mathbf{X}_{2}$ & 0,919 & 1,000 & 0,866 & 0,909 \\
\hline $\mathbf{X}_{3}$ & 0,917 & 0,866 & 1,0000 & 0,971 \\
\hline $\mathbf{Y}$ & 0,950 & 0,909 & 0,971 & 1,000 \\
\hline
\end{tabular}


3. Matriks korelasi antar variabel eksogen

Tabel 2

Matrix Korelasi Antar Variabel eksogen

\begin{tabular}{cccc}
\hline & $\mathbf{X}_{1}$ & $\mathbf{X}_{2}$ & $\mathbf{X}_{3}$ \\
\hline $\mathbf{X}_{1}$ & 1,000 & 0,919 & 0,917 \\
\hline $\mathbf{X}_{2}$ & 0,919 & 1,000 & 0,866 \\
\hline $\mathbf{X}_{3}$ & 0,917 & 0,866 & 1,000 \\
\hline
\end{tabular}

4. Matrix Invers Korelasi Antara Variabel X

Tabel 3

Matrix Invers Antara Variabel $X$

\begin{tabular}{cccc}
\hline & $\mathbf{X}_{1}$ & $\mathbf{X}_{2}$ & $\mathbf{X}_{3}$ \\
\hline $\mathbf{X}_{1}$ & 10,417 & $-5,208$ & $-5,042$ \\
\hline $\mathbf{X}_{2}$ & $-5,208$ & 6,625 & $-0,958$ \\
\hline $\mathbf{X}_{3}$ & $-5,042$ & $-0,958$ & 6,458 \\
\hline
\end{tabular}

Sumber : Hasil data pengolahan pada Prelis

5. Koefisien Jalur $\rho \mathbf{X}_{1}=0 \quad \mathrm{i}=12,23$

Tabel 4

Koefesien jalur

\begin{tabular}{cc}
\hline$\rho_{y \times 1}$ & 0,270 \\
\hline$\rho_{y \times 2}$ & 0,139 \\
$\rho_{y \times 3}$ & 0,603 \\
\hline
\end{tabular}

Sumber : Hasil data pengolahan pada Prelis

6. Koefisien Determinasi Multiple

$\mathrm{R}^{2} \mathrm{Y}\left(\mathrm{X}_{1} \mathrm{X}_{2} \mathrm{X}_{3}\right)$

Untuk mengetahui pengaruh simultan variabel bebas $\left(\mathrm{X}_{1} \mathrm{X}_{2}, \mathrm{X}_{3}\right)$ terhadap variabel terikat $(\mathrm{Y})$ maka digunakan rumus sebagai berikut:

Menghitung Koefisien Determinasi Multiple $\mathrm{R}^{2}$

$$
\begin{gathered}
\mathrm{R}^{2} \mathrm{Y}\left(\mathrm{X}_{1,} \mathrm{X}_{2} \mathrm{X}_{3}\right)=\left(\begin{array}{lll}
0,270 & 0,139 & 0,603
\end{array}\right)\left[\begin{array}{l}
0,950 \\
0,909 \\
0,971
\end{array}\right]=0,968 \\
\mathrm{R}^{2} \mathrm{Y}\left(\mathrm{X}_{1} \mathrm{X}_{2} \mathrm{X}_{3}\right)=0,968 \times 100 \%=96,8 \%
\end{gathered}
$$

Dari perhitungan di atas didapat pengaruh secara keseluruhan dari variabel $\mathrm{X}_{1} \mathrm{X}_{2}, \mathrm{X}_{3}$ terhadap Y sebesar 96,8\%.

\section{Pengaruh Variabel Lain}

Menghitung pengaruh variabel lain yang secara tidak langsung mempengaruhi variabel Y selain variabel $X_{1}, X_{2}, X_{3}$

$$
\rho \mathrm{Y} \varepsilon=\sqrt{1-0,968}=\sqrt{0,032}=0,17889
$$

\section{KESIMPULAN}

Berdasarkan hasil penelitian yang telah dilakukan pada Kantor Pelayanan Pajak (KPP) Kota Banjarmasin maka penulis menarik beberapa kesimpulan antara lain:

1. Menyampaikan dan mengisi formulir pajak dengan lengkap dan jelas, menghitung jumlah pajak yang terutang dengan benar, membayar pajak yang terutang tepat pada waktunya secara parsial memiliki pengaruh positif dan tidak signifikan. Hal ini disebabkan masih rendahnya kepatuhan Wajib Pajak dalam mematuhi peraturan perundang-undangan perpajakan dan Wajib Pajak sendiri mengalami kesulitan dalam hal pengisian Surat Pemberitahuan (SPT) karena sering berubahnya peraturan perpajakan yang selalu mengikuti perkembangan dunia ekonomi.

2. Dari hasil perhitungan mengenai hubungan antara menyampaikan dan mengisi formulir pajak dengan lengkap dan jelas $\left(\mathrm{X}_{1}\right)$, menghitung jumlah pajak yang terutang dengan benar $\left(\mathrm{X}_{2}\right)$, membayar pajak yang terutang tepat pada waktunya $\left(\mathrm{X}_{3}\right)$ terdapat hubungan korelasional yang kuat sehingga hubungan diantara ketiganya terdapat multikoleniaritas.

3. Iklim perpajakan, yaitu menyampaikan dan mengisi formulir pajak dengan lengkap dan jelas, menghitung jumlah pajak yang terutang dengan benar, membayar pajak yang terutang tepat pada waktunya secara keseluruhan memilki pengaruh yang positif dan signifikan terhadap penerimaan pajak penghasilan badan. 


\section{REFERENSI}

Eric, Suwarta, 2004, Tax Planning, JMT House

Erly Suandy, 2006, Perpajakan (Dilengkapi dengan Latihan Soal). Edisi Revisi. Penerbit salemba Empat. Jakarta.

2002, Hukum Pajak (Dilengkapi dengan Latihan Soal). Edisi kedua (Revisi). Penerbit Salemba Empat. Jakarta.

Gunadi, 2001, Ketentuan Umum Perpajakan, Sesuai dengan UU No. 16 Tahun 2000, PT. Multi Utama Consultindo. Jakarta

Gunadi, Jurnal Perpajakan Indonesia, Volume 4, Nomor 5, Februari 2005:4-9

Harun Al-Rasjid, 2009, Analisis Jalur (Path Analisys), Diktat Program Pascasarjana UNPAD, Bandung.

Keputusan Menteri Keuangan Indonesia No. 534/KMK.04/2016, Tentang bentuk dan isi SPT serta keterangan dan atau Dokumen yang harus dilampirkan.

Kusnadi, Siti Maria, Ririn Irmadariyani, 2012, Akuntansi Keuangan Menengah (Intermediate) (Prinsip, Prosedur dan Metode), Universitas Brawijaya, Malang..

Mardiasmo, 2016, Perpajakan, Edisi Revisi, Andi Yogyakarta

Mohammad Zain, 2009, Manajemen Perpajakan, Bandung : Salemba Empat.

Nowark Norman D., 2015, Tax Administration in Theory and Practise With Special Reference to Chile, New York, Washington, London: Praeger Publisher

Nur Indrianto dan Bambang Supomo, 2015, Metode Penelitian Bisnis: Untuk Akuntansi dan Manajemen, BPFE. Yogyakarta.

Rimsky K. Judisseno, 2015, Pajak dan Strategi Bisnis suatu Tinjauan tentang kepastian Hukum dan Penerapan Akuntansi di Indonesia, Penerbit PT gramedia Pustaka utama Jakarta.

Waluyo, Wirawan B. Ilyas, 2002. Perpajakan Indonesia, Jakarta: Salemba Empat. 